\title{
Conjugated linoleic acid influences the metabolism of tocopherol in lactating rats but has little effect on tissue tocopherol concentrations in pups
}

\author{
Johanna O. Zeitz*, Erika Most and Klaus Eder
}

\begin{abstract}
Background: Conjugated linoleic acid (CLA) is known to affect the lipid metabolism in growing and lactating animals. However, potential effects on the metabolism of fat-soluble vitamins in lactating animals and co-occurring effects on their offspring are unknown. We aimed to investigate the effects of dietary CLA on concentrations of tocopherol in various tissues of lactating rats and their offspring and expression of genes involved in tocopherol metabolism.

Methods: Twenty-eight Wistar Han rats were allocated to 2 groups and fed either a control diet (control group) or a diet containing $0.9 \%$ of cis-9, trans-11 and trans-10, cis-12 (1:1) CLA (CLA group) during pregnancy and lactation. Feed intake of dams and body weight of dams and their pups were recorded weekly. Tocopherol concentrations in various body tissues were determined at day 14 of lactation in dams and 1,7 and 14 days after birth in pups. Expression of selected genes involved in metabolism of tocopherol was determined in dams and pups. The data were statistically analysed by analysis of variance.
\end{abstract}

Results: Feed intake and body weight development of nursing rats and their pups was similar in both groups. In livers of CLA-fed dams, tocopherol concentrations decreased by $24 \%$ but expression of TTPA and CYP3A1, involved in tocopherol transport and metabolism, were not influenced. In the dams' adipose tissue, gene expression of receptors involved in tissue tocopherol uptake, LDLR and SCARB1, but not of LPL, increased by 30 to $50 \%$ and tocopherol concentrations increased by $47 \%$ in CLA-fed compared to control dams. Expression of LPL, LDLR and SCARB1 in mammary gland was not influenced by CLA-feeding. Tocopherol concentrations in the pup's livers and lungs were similar in both groups, but at 14 days of age, adipose tissue tocopherol concentrations, and LDLR and SCARB1 expression, were higher in the CLA-exposed pups.

Conclusions: We show that dietary CLA affects tissue concentrations of tocopherol in lactating rats and tocopherol metabolism in rats and pups, but hardly influences tissue tocopherol concentrations in their offspring. This indicates that supplementation of CLA in pregnant and lactating animals is uncritical considering the tocopherol status of new-borns.

Keywords: Conjugated linoleic acid, Lactating rat, Vitamin metabolism, Tocopherol

\footnotetext{
* Correspondence: Johanna.O.Zeitz@ernaehrung.uni-giessen.de University of Giessen, Institute of Animal Nutrition and Nutritional Physiology, Heinrich-Buff-Ring 26-32 (IFZ), D-35392 Giessen, Germany
} 


\section{Background}

Dietary CLA supplements, which usually consist of a mixture of the cis-9, trans-11 CLA and the trans-10, cis-12 CLA isomer, are known to influence the lipid metabolism during lactation and growth in different species like rats $[1,2]$, pigs [3] and ruminants [4, 5]. The CLA influence the lipid metabolism by down regulating gene expression of proteins involved in lipid synthesis and fatty acid (FA) transport in many tissue like muscle, adipose tissue, liver $[1,3]$ and mammary gland $[4,6]$. Consequently, the FA composition of tissues and milk is altered by CLA $[1,4,5]$. Similarly, CLA might influence the metabolism of tocopherols, which is linked to the lipid metabolism concerning absorption and intermediary metabolism [7]. For example, tocopherols are emulsified by bile acids in the intestine and transported in chylomicrons and lipoproteins together with other lipids [7]. Likewise, the lipoprotein lipase (LPL) is not only crucial for uptake of triglycerides (TG) and FA from chylomicrons and very low density lipoproteins (VLDL) into extra-hepatic tissues [8], but it is also important for uptake of tocopherols [7]. Some first studies in growing animals indicate that feeding CLA in fact influences tissue tocopherol concentrations. For example, in the liver of mice and rats, levels of $\alpha$-tocopherol increased when CLA was supplemented to the diet $[9,10]$. The molecular mechanism underlying these observations are largely unknown but may be related to increased levels of the $\alpha$-tocopherol transfer protein (TTPA) which is responsible for retaining $\alpha$-tocopherol in the body [9]. Increased concentrations of $\alpha$-tocopherol in plasma and adipose tissue due to CLA feeding have been found as well $[9,10]$. Tocopherol has not only important functions as an antioxidant but also e.g., in cell signalling and inflammation [7]. When changes in tocopherol status due to CLA feeding occur, this may affect not only the animal fed CLA, but, in case of pregnant and lactating animals, also growth and development of their offspring. However, studies investigating the tocopherol metabolism in response to CLA feeding in lactating animals and potential effects on their offspring are missing so far. We hypothesized that dietary CLA influences the tocopherol status of lactating rats and their offspring. Therefore, we determined tocopherol concentrations in various tissues of dams and their pups. Furthermore, we aimed to reveal the molecular mechanisms underlying the observed changes in tissue tocopherol status by investigating gene expression of selected enzymes and cell membrane receptors involved in the metabolism of tocopherol.

\section{Methods}

\section{Animal experiment}

Twenty-eight female Wistar Han rats were obtained from Harlan Laboratories (AN Venray, The Netherlands) at their $2^{\text {nd }}$ day of pregnancy. The rats were randomly assigned to 2 groups of 14 rats each, with an initial body weight of $220 \pm 16.2 \mathrm{~g}$ (mean $\pm \mathrm{SD}$; Control group) and $218 \pm 18.5$ g (CLA group) $(P=0.75)$. The pregnant rats were housed in groups of 2 animals each in Macrolon cages (type 4) enriched with cellulose papers and a cardboard tube in a room controlled for temperature (22 \pm $\left.2{ }^{\circ} \mathrm{C}\right)$, relative humidity $(55 \pm 10 \%)$, ventilation $(20 / \mathrm{h})$, and light (12-h-light/-dark cycle, <200 Lux). Water was available ad libitum from nipple drinkers during the whole experiment. Bedding was exchanged every week. Experimental diets were fed during pregnancy and lactation. The rats were fed semipurified diets meeting their nutrient requirements according to the recommendations of the National Research Council for the AIN-93G diet [11] (Table 1). Titanium dioxide $\left(\mathrm{TiO}_{2}\right)$ was added at $0.5 \%$ of the diet to determine the apparent total tract digestibility of tocopherol. The CLA supplement Lutalin ${ }^{\odot}$ (BASF, Ludwigshafen, Germany), which contained $29 \%$ each of the cis-9, trans-11 and the trans-10, cis-12 CLA isomer (data not shown), replaced part of the soybean oil and was supplemented in a dosage of $15 \mathrm{~g} / \mathrm{kg}$ diet in the CLA group (Table 1). In the control group, linoleic acid rich sunflower oil (15 g/kg diet) replaced part of the soybean oil to approximate dietary FA other than

Table 1 Ingredients and concentrations of individual tocopherols in the experimental diets

\begin{tabular}{|c|c|c|}
\hline & Control diet & CLA diet \\
\hline \multicolumn{3}{|l|}{ Ingredient, g/kg diet } \\
\hline Corn starch & 532 & 532 \\
\hline Casein & 200 & 200 \\
\hline Sucrose & 100 & 100 \\
\hline Cellulose & 50 & 50 \\
\hline Soybean oil & 55 & 55 \\
\hline Sunflower oil & 15 & - \\
\hline CLA supplement (Lutalin $\left.{ }^{\circledast}\right)$ & - & 15 \\
\hline Mineral mix ${ }^{a}$ & 35 & 35 \\
\hline Vitamin mix ${ }^{a}$ & 10 & 10 \\
\hline L-Cysteine & 3 & 3 \\
\hline \multicolumn{3}{|c|}{ Dietary tocopherol concentration $(\mu \mathrm{mol} / \mathrm{kg} \text { diet })^{\mathrm{b}}$} \\
\hline a-tocopherol & $140 \pm 3.28$ & $141 \pm 2.02$ \\
\hline y-tocopherol & $60.4 \pm 1.30$ & $59.8 \pm 1.43$ \\
\hline 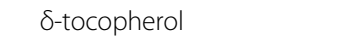 & $6.57 \pm 0.37$ & $6.58 \pm 0.22$ \\
\hline Tocopherol equivalents ${ }^{c}$ & $147 \pm 3.28$ & $147 \pm 2.01$ \\
\hline
\end{tabular}

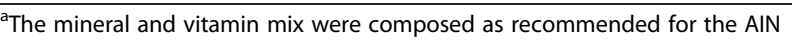
$93 \mathrm{G}$ diet by Reeves et al. [11]

${ }^{\mathrm{b}}$ means \pm standard deviations of 5 analyses of feed samples collected in weeks 1 to 5 . The $\beta$ - and $\delta$-tocopherols, which are quantitatively negligible as source of active vitamin $E$ in soybean and sunflower oil [32], could not be separated by HPLC and are summarized as $\delta$-tocopherol

$c_{\text {sum }}$ of active $a, \delta$ - and $\gamma$-tocopherol considering conversion factors of 0.10 for $\gamma$-tocopherol and 0.03 for $\delta$-tocopherol as compared to a-tocopherol (100\% active) [17] 
linoleic acid and CLA in both experimental diets. The CLA supplement contained $12.8 \mathrm{~g}$ of total CLA/100 g of dietary FAs which is equivalent to $0.9 \mathrm{~g}$ CLA/ $100 \mathrm{~g}$ of diet. Diets were pelleted to $10 \mathrm{~mm}$ with a standard pelleting device (Kahl Laborpressanlage Typ 14-175, Reinbek, Germany). Feed was offered ad libitum and intake was recorded weekly. After parturition, rats were individually housed together with their pups. Litters were adjusted to 8 pups per dam without differentiation of gender after a maximum of 3 days after parturition. Two dams from the control group were removed from the experiment because 1 dam devoured the whole litter directly after parturition and 1 dam had to be killed due to problems with delivery. All experimental procedures were in strict accordance with the Appendix A of European Convention for the Protection of Vertebrate Animals used for Experimental and other Scientific Purposes (ETS NO. 123). In Accordance with Article 4 par. 3 of the German Animal Welfare Law all animals were humanely killed for scientific purposes which was approved by the Animal Welfare Officer of the JustusLiebig-University, JLU No. 480_M.

\section{Sample collection}

Feed samples were taken weekly and stored at $-20{ }^{\circ} \mathrm{C}$ for later tocopherol and FA analysis. Feed intake and weights of rats and their litter were recorded weekly. Within $24 \mathrm{~h}$ after birth, 2 randomly chosen pups/litter were decapitated and liver, lung, and the milk curd from the stomach were removed. After 7 days, 1 pup/litter was anesthetized with isoflurane, decapitated, and liver, lung, subcutaneous fat and the milk curd from the stomach were removed. At day 13 of lactation, the dam's feces, which had been excreted during the preceding $24 \mathrm{~h}$, was collected and stored at $-20{ }^{\circ} \mathrm{C}$. At day 14, i.e., at peak lactation and before weaning [12, 13], all dams and the remaining pups were decapitated under anaesthesia with carbon dioxide. From the pups, liver, lung, subcutaneous fat and the milk curd from the stomach were removed. Blood from the dams was collected into heparinised polyethylene tubes (Sarstedt) and plasma was separated by centrifugation $(1100 \times g, 10 \mathrm{~min})$ at $4{ }^{\circ} \mathrm{C}$ and stored at $-20{ }^{\circ} \mathrm{C}$. From the dams, liver, mammary gland (right), gastrocnemius muscle (left) and kidney fat (left) were excised. All tissue samples were immediately snapfrozen in liquid nitrogen and stored at $-80{ }^{\circ} \mathrm{C}$ pending further analysis.

\section{Determination of tissue lipid content and of fatty acid composition}

For milk curd fat determination, about $0.2 \mathrm{~g}$ of lyophilized milk curd was dispersed with $3 \mathrm{~mL}$ of $0.9 \% \mathrm{NaCl}$ and the fat was extracted with $4 \mathrm{~mL}$ hexane: isopropanol (HiP, 3:2, $\mathrm{v} / \mathrm{v}$ ) [14] overnight. After centrifugation at $1000 \times g$ for
5 min at $15{ }^{\circ} \mathrm{C}$, the upper fat-containing phase was quantitatively transferred to a dried and weighed test glass and the fat extraction procedure was repeated once. The test glass was dried to constant weight at $105{ }^{\circ} \mathrm{C}$ and reweighed and the weighed fat was related to the initial milk curd weight. Feed and liver FA composition was determined according to Schlegel et al. [5]. In brief, $0.25 \mathrm{~g}$ of milled feed or dietary oil or $50 \mathrm{mg}$ of homogenized liver tissue was extracted with 4 or $0.5 \mathrm{~mL}$ of $\mathrm{HiP}(3: 2, \mathrm{v} / \mathrm{v})$, respectively, excluding light overnight on a shaker. After centrifugation $\left(10 \mathrm{~min}\right.$ at $15{ }^{\circ} \mathrm{C}$ and $\left.1000 \times \mathrm{g}\right), 250$ (feed), 50 (oil) or $100 \mu \mathrm{L}$ (liver) of the upper fat-containing phase was evaporated to dryness under $\mathrm{N}_{2}$ at $37{ }^{\circ} \mathrm{C}$ and methylated with 50 (feed, liver) or $150 \mu \mathrm{L}$ (oil) of trimethylsulfonium hydroxide [15]. The fatty acid methyl esters were separated by gas chromatography using a PE Clarus 580 system (Perkin Elmer, US) equipped with an automatic split injector, a polar capillary column $(50 \mathrm{~m}, 0.25 \mathrm{~mm}$ i.d., $0.2 \mu \mathrm{m}$ film thickness; Macherey and Nagel, Düren, Germany), and a flame ionization detector. Helium was used as carrier gas (flow rate $1.2 \mathrm{~mL} / \mathrm{min}$ ). The individual fatty acid methyl esters were identified by comparing their retention times with those of purified standards. The $\Delta-9$ and $\Delta-6$ desaturase indices were calculated to estimate desaturase activities according to Masek et al. [16].

\section{Determination of tocopherols}

Concentrations of tocopherols in feed, feces, plasma, tissue and milk curd were determined by high-performance liquid chromatography (HPLC) (L-7100, LaChrom, Merck-Hitachi, Darmstadt, Germany). Samples of $0.1 \mathrm{~g}$ of feed, feces, homogenized tissue or milk curd or of $0.2 \mathrm{~mL}$ of plasma, were mixed with $2 \mathrm{~mL}$ of a $10 \mathrm{~g} / \mathrm{L}$ pyrogallol solution (in ethanol, absolute) and $300 \mu \mathrm{L}$ of a saturated sodium hydroxide solution. After flushing with $\mathrm{N}_{2}$, this mixture was heated for $30 \mathrm{~min}$ at $70{ }^{\circ} \mathrm{C}$ in closed glass tubes. The tocopherols were then extracted by addition of $2 \mathrm{~mL}$ of $\mathrm{n}$-hexane and $2 \mathrm{~mL}$ of bidest. water. After centrifugation $\left(5 \mathrm{~min}\right.$ at $10{ }^{\circ} \mathrm{C}$ and $1000 \times \mathrm{g}$ ), an aliquot of the hexane phase was evaporated to dryness under $\mathrm{N}_{2}$ and redissolved in methanol containing $0.05 \%$ of butylated hydroxytoluene. The tocopherols were separated isocratically by HPLC using methanol as mobile phase, a C18 column $(\geq 3 \mu \mathrm{m}$ particle size, $4 \mathrm{~mm}$ length, $2 \mathrm{~mm}$ internal diameter, Phenomenex, Germany) (pre-column) and a C18-reversed phase column (Luna C18 (2), 150*4.6 mm; Phenomenex, Aschafffenburg, Germany) and detected by fluorescence (Fluorescence Detector L-7480, LaChrom, Merck-Hitachi). Excitation and emission wavelengths for tocopherols were 295 and $325 \mathrm{~nm}$, respectively. Tocopherol equivalents were calculated using the stereoisomer of $\alpha$-tocopherol, RRR $\alpha$-tocopherol, as a reference (RRR $\alpha$-tocopherol $=1$ ), and $\gamma$-tocopherol was multiplied by 
0.10 and $\delta$-tocopherol by 0.03 to consider the lower vitamin activity of those 2 tocopherol isomers [17].

\section{Determination of tocopherol digestibility}

The apparent total tract digestibility of tocopherol was determined using $\mathrm{TiO}_{2}$ as an indigestible marker. The $\mathrm{TiO}_{2}$ concentrations in feed and feces were measured photometrically according to Brandt and Allam [18] and the digestibility was calculated as: apparent total tract digestibility $=100-\left\{\left(\% \mathrm{TiO}_{2}\right.\right.$ in diet $/ \% \mathrm{TiO}_{2}$ in feces $) \times(\%$ tocopherol in feces/\% tocopherol in diet) $\times 100\}$.

\section{RNA isolation and Quantitative real-time RT-PCR}

Total RNA was isolated from $20 \mathrm{mg}$ of liver tissue (dams, pups) using Trizol reagent (Invitrogen) according to the manufacturer's protocol and from $80 \mathrm{mg}$ of kidney fat (dams) or subcutaneous fat (pups), or from $40 \mathrm{mg}$ of mammary gland tissue (dams) using the RNeasy Lipid Tissue Mini Kit (Qiagen, Hilden, Germany). The RNA concentration and purity were estimated from the optical density at 260 and $280 \mathrm{~nm}$, respectively, using an Infinite $200 \mathrm{M} \mathrm{mi-}$ croplate reader and a NanoQuant Plate (both from Tecan, Männedorf, Switzerland) and RNA was stored at $-80{ }^{\circ} \mathrm{C}$. The cDNA was synthesized from $1.2 \mu \mathrm{g}$ of total RNA using 100 pmol dT18 primer (Eurofins MWG Operon, Ebersberg, Germany), $1.25 \mu \mathrm{L} 10 \mathrm{mmol} / \mathrm{L}$ dNTP mix (GeneCraft, Lüdinghausen, Germany), $5 \mu \mathrm{L}$ buffer (Fermentas, St. Leon-Rot, Deutschland), and 60 units MMuLV Reverse Transcriptase (MBI Fermentas, St. LeonRot, Germany) at $42{ }^{\circ} \mathrm{C}$ for $60 \mathrm{~min}$, and a final inactivating step at $70{ }^{\circ} \mathrm{C}$ for $10 \mathrm{~min}$ in Biometra ThermalCycler (Whatman BiometraW, Göttingen, Germany). The cDNA was diluted 1:2 with DNase/RNase free water and stored at $-20{ }^{\circ} \mathrm{C}$. The $\mathrm{qPCR}$ was carried out on a Rotorgene 2000 system (Corbett Research, Mortlake, Australia) using $2 \mu \mathrm{L}$ cDNA combined with $9 \mu \mathrm{L}$ of a mixture composed of $5 \mu \mathrm{L}$ KAPA SYBR FAST qPCR Universal Mastermix (Peqlab, Erlangen, Germany), $0.2 \mu \mathrm{L}$ each of $10 \mu \mathrm{M}$ forward and reverse primers and $3.6 \mu \mathrm{L}$ DNase/RNase free water in $0.1 \mathrm{~mL}$ tubes (Ltf Labortechnik, Wasserburg, Germany). Gene-specific primer pairs were from [19] or were designed using PRIMER3 and BLAST and obtained from Eurofins MWG Operon (Ebersberg, Germany) (Table 2). The amplification of a single product of the expected size was approved using $2 \%$ agarose gel electrophoresis stained with GelRed ${ }^{\mathrm{Tm}}$ nucleic acid gel stain (Biotium Inc., Hayward, CA). The Ct values of target and reference genes were obtained using Rotorgene Software 5.0 (Corbett Research). All Ct values were transformed into relative quantification data using the $2^{-\Delta \mathrm{Ct}}$ equation [20] but the efficiencies of the reference and target genes were determined and used for the calculations instead of using an efficiency of 2. The highest relative quantities for each gene were set to 1 . These expression values of target genes were normalized using the GeNorm normalization factor [21]. Using the Microsoft Excel-based application GeNorm, the GeNorm normalization factor was calculated as the geometric mean of expression data (relative quantities) of the three most stable out of four to six tested potential reference genes (ATP5B, CANX, MDH1, RPL13, TOP1, YW HAZ for liver and fat; ACTB instead of ATP5B for mammary gland). The normalized expression values data set was corrected for outliers. Means and SD were calculated from normalized expression data for samples of the same

Table 2 Characteristics of primers used for qPCR

\begin{tabular}{|c|c|c|c|c|c|c|}
\hline Gene & $\begin{array}{l}\text { GeneBank } \\
\text { accession no. }\end{array}$ & Sense primer $\left(5^{\prime}-3^{\prime}\right)$ & Antisense primer $\left(5^{\prime}-3^{\prime}\right)$ & Product size, bp & Primer efficiency & Annealing Temp., ${ }^{\circ} \mathrm{C}$ \\
\hline \multicolumn{7}{|c|}{ Reference genes } \\
\hline ACTB & NM_031144.2 & GACCTCTATGCCAACACAGT & CACCAATCCACACAGAGTAC & 154 & 1.92 & 60 \\
\hline ATP5B & NM_134364.1 & GCACCGTCAGAACTATTGCT & GAATTCAGGAGCCTCAGCAT & 203 & 1.90 & 60 \\
\hline CANX & NM_172008.2 & CCAGATGCAGATCTGAAGAC & CTGGGTCCTCAATTTCACGT & 175 & 2.31 & 60 \\
\hline $\mathrm{MDH} 1$ & NM_033235.1 & CAGACAAAGAAGAGGTTGCC & CGTCAGGCAGTTTGTATTGG & 206 & 1.97 & 60 \\
\hline RPL13 & NM_031101.1 & CTTAAATTGGCCACGCAGCT & CTTCTCAACGTCTTGCTCTG & 198 & 1.94 & 60 \\
\hline TOP1 & NM_022615.1 & GAAGAACGCTATCCAGAAGG & GCTTTGGGACTCAGCTTCAT & 137 & 2.00 & 60 \\
\hline YWHAZ & NM_013011.3 & GACGGAAGGTGCTGAGAAA & GCAGCAACCTCAGCCAAGT & 198 & 2.09 & 60 \\
\hline \multicolumn{7}{|c|}{ Target genes } \\
\hline TTPA & NM_013048.2 & GGAGGTGGAAACTCAACGGAA & AGCAGCAATCTTCTTGGCTACA & 109 & 1.93 & 60 \\
\hline CYP3A1 & NM_013105.2 & TGGTAATAGACTTGAGAGAG & GGGCAGATATACATAAGGA & 196 & 1.90 & 56 \\
\hline LDLR & NM_175762.2 & ACAGTGTCCTCCCAAGTCCAA & GCAAATGTGGATCTCGTCCTC & 222 & 1.87 & 60 \\
\hline SCARB1 & NM_031541.1 & GGTGCCCATCATTTACCAAC & CCCTACAGCTTGGCTTCTTG & 162 & 1.94 & 60 \\
\hline LPL & NM_012598.2 & GAGATITCTCTGTATGGCACA & CTGCAGATGAGAAACTTTCTC & 276 & 1.99 & 60 \\
\hline
\end{tabular}

Primers were designed using Primer3 from gene sequences obtained from GeneBank and tested in silico using BeaconDesigner and mfold. Primer specificity was determined using a BLAST search 
experimental group. The mean of the control group was set to 1 and the means and SD of the CLA group was scaled proportionally.

\section{Statistics}

Data were analysed by one-way analysis of variance using the software $\mathrm{R}$ version 3.1.3 (https://cran.r-project.org). For analysis of data with measurements at only one time point, treatment was considered as fixed and animal as random effect and the function lme, package nlme, was used. Time-series data were monitored over time; the model included treatment, time and their interaction as fixed effects and animal as random effect using lmer; pairwise comparisons were done using the Hochberg test and the function lsmeans.

\section{Results}

Tocopherol and fatty acid composition of the diet The concentration of tocopherols were similar in both diets (Table 1). The FA composition of the experimental diets is shown in Table 3. As intended, the FA composition of the 2 experimental diets was similar and differed only in their contents of CLA and linoleic acid (Table 3).

\section{Effects of CLA on performance, liver lipids, tocopherol} digestibility, and tissue tocopherol concentration of dams Feed intake was similar in control and CLA-fed rats, but increased after delivery with the onset of lactation in both groups (Table 4). Consequently, the dietary intake of tocopherols increased with the onset of lactation in week 4 but was similar between groups (Table 4). Body weight development of dams before and after delivery was not influenced by the supplementation of CLA to the diet (Table 4). After 5 experimental weeks, at peak lactation, dam liver weights (\% of body weight) were similar in both groups, however, liver TG concentrations were lower in

Table 3 FA composition of the control and CLA-supplemented diet $\left(\mathrm{g} / 100 \mathrm{~g}\right.$ of total FAs) ${ }^{\mathrm{a}}$

\begin{tabular}{llr}
\hline & Control diet & \multicolumn{1}{c}{ CLA diet } \\
\hline C 16:0 & $10.04 \pm 0.02$ & $10.04 \pm 0.06$ \\
C 18:0 & $3.22 \pm 0.04$ & $3.38 \pm 0.07$ \\
C 18:1 n9 & $22.51 \pm 0.21$ & $22.91 \pm 0.09$ \\
C 18:1 n7 & $1.37 \pm 0.01$ & $1.38 \pm 0.01$ \\
C 18:2 n6 & $57.51 \pm 0.17$ & $45.04 \pm 0.32$ \\
C 18:3 n3 & $4.43 \pm 0.11$ & $4.46 \pm 0.09$ \\
C18:2 cis-9, trans-11 CLA & $<0.1$ & $6.04 \pm 0.21$ \\
C18:2 trans-10, cis-12 CLA & $<0.1$ & $5.82 \pm 0.21$ \\
C 20:0 & $0.25 \pm 0.01$ & $0.27 \pm 0.01$ \\
C 20:1 & $0.19 \pm 0.01$ & $0.21 \pm 0.01$ \\
C 20:5 n3 & $0.42 \pm 0.02$ & $0.41 \pm 0.02$ \\
\hline a 2 . &
\end{tabular}

${ }^{a}$ mean \pm standard deviation of 5 analyses for diets (samples of week 1-5)
CLA-fed dams compared to control dams (Table 5). The FA composition of total liver lipids differed between groups (Table 5). As expected, the concentrations of both CLA isomers and of stearic acid were higher in the CLA group as compared to the control group while the concentrations of mono- and polyunsaturated C18 FAs including linoleic acid were lower (Table 5 ). In addition, $\Delta-9$ and $\Delta$ 6 desaturase indices, i.e., the estimated desaturase activities, were lower in the CLA-fed groups compared to the control group (Table 5). The apparent digestibility of tocopherol was considerably lower in the CLA-fed dams than in the Control dams (Table 6). Still, concentrations of tocopherols in plasma and muscle of dams were not influenced by CLA feeding (Table 6). However, the tocopherol concentration in the liver decreased by $24 \%$ in the CLAfed dams whereas that in the adipose tissue increased by $47 \%$ (Table 6). Both fat and tocopherol concentrations in the milk curd were similar in both groups (Table 7). Tocopherol concentrations in milk curd were highest one day after delivery and decreased during the first 2 weeks of lactation (Table 7).

\section{Effects of CLA on performance and tissue tocopherol concentration of pups}

At delivery, litter weights were similar in the control $(67.8 \pm 14.0 \mathrm{~g})$ and the CLA group $(69.0 \pm 16.3 \mathrm{~g})(P=$ $0.85)$. Litter size did not differ between the control $(11.2 \pm 2.33$ pups per litter) and CLA group (11.0 \pm $3.06)$ as well $(P=0.88)$. All 26 rats used for data analysis delivered within 3 days and litter size was standardized to 8 pups per dam on average 1.1 days after birth (maximum 2 days after birth). Litter development after litter size standardization was similar in both groups (Table 7). Liver weights were similar between groups both in the newborn pups and in 14 day-old pups (Table 7). Likewise, weights of the lung were similar in pups nursed by CLA-fed dams $(2.28 \pm 0.42 \mathrm{~g} / 100 \mathrm{~g} \mathrm{BW})$ and in pups nursed by Control dams $(2.45 \pm 0.62 \mathrm{~g} / 100 \mathrm{~g} \mathrm{BW})(P=0.42)$. The tocopherol concentration in livers and lungs of pups did not differ between the two groups, but were higher in new-born pups as compared to 7 and 14 day-old pups (Table 7 ). In the adipose tissue, concentrations of tocopherols were higher in the CLA group as compared to the control group in the 14 day-old pups, but did not differ in the 7-day old pups (Table 7 ).

\section{Effects of CLA on expression of genes involved in metabolism of lipids and tocopherols in liver, adipose tissue and mammary gland of dams and pups}

In the liver of dams at day 14 of lactation, the gene expression of TTPA was similar in both groups, and the CLA supplement did also not influence the expression of CYP3A1, a cytochrome P450 enzyme which is important for tocopherol degradation in rat liver [22, 23] 
Table 4 Feed and tocopherol intake and body weight of dams fed either a control or a CLA-supplemented diet ${ }^{d}$

\begin{tabular}{|c|c|c|c|c|c|c|c|c|c|}
\hline & \multicolumn{5}{|l|}{ Week } & \multirow[t]{2}{*}{ SEM } & \multicolumn{3}{|l|}{$P$ value } \\
\hline & 1 & 2 & 3 & 4 & 5 & & Treatment & Time & tr.*time \\
\hline \multicolumn{10}{|c|}{ Feed intake, $\mathrm{g} / \mathrm{d}$} \\
\hline Control & $21.7^{\mathrm{a}}$ & $20.8^{\mathrm{a}}$ & $21.9^{\mathrm{a}}$ & $25.2^{\mathrm{b}}$ & $43.2^{c}$ & 0.57 & 0.43 & $<0.001$ & 0.25 \\
\hline CLA & $21.1^{\mathrm{a}}$ & $20.4^{a}$ & $20.8^{\mathrm{a}}$ & $26.5^{\mathrm{b}}$ & $43.8^{c}$ & & & & \\
\hline \multicolumn{10}{|c|}{ Tocopherol intake, $\mu \mathrm{mol} / \mathrm{d}^{\mathrm{e}}$} \\
\hline Control & $3.18^{\mathrm{a}}$ & $3.05^{\mathrm{a}}$ & $3.21^{\mathrm{a}}$ & $3.69^{b}$ & $6.33^{c}$ & 0.08 & 0.99 & $<0.001$ & 0.40 \\
\hline CLA & $3.09^{\mathrm{a}}$ & $2.99^{a}$ & $3.05^{\mathrm{a}}$ & $3.88^{\mathrm{b}}$ & $6.41^{c}$ & & & & \\
\hline \multicolumn{10}{|c|}{ Body weight, $g$} \\
\hline Control & $258^{\mathrm{a}}$ & $292^{b}$ & $286^{\mathrm{b}}$ & $294^{b}$ & $289^{\mathrm{b}}$ & 4.9 & 0.95 & $<0.001$ & 0.75 \\
\hline CLA & $256^{\mathrm{a}}$ & $293^{b}$ & $283^{b}$ & $289^{b}$ & $285^{\mathrm{b}}$ & & & & \\
\hline
\end{tabular}

${ }^{\mathrm{a}-\mathrm{c}}$ Means with superscripts without a common letter differ at $P<0.05$. ${ }^{\mathrm{d}}$ Values are means, $n=12-14$. Means with superscripts without a common letter differ at $P<0.05$. Weeks 1-3: pregnancy, weeks 4-5: lactation; weight for week 3 is after delivery; tr., treatment. Data were analysed by two-way ANOVA with treatment, time and their interaction as fixed effects and animal as random effect

${ }^{e}$ sum of active $a, \delta$ - and $\gamma$-tocopherol considering conversion factors of 0.10 for $\gamma$-tocopherol and 0.03 for $\delta$-tocopherol as compared to a-tocopherol (100 \% active) [17]

(Fig. 1a). In the adipose tissue, the gene expression of LDLR and SCARB1, which are involved in uptake of lipoproteins and lipid-soluble vitamins, were enhanced by 50 and $30 \%$, respectively, in the CLA group as compared to the control group, but the expression of LPL was similar (Fig. 1b). In liver and mammary gland, the gene expression of LDLR, SCARB1 and LPL was similar

Table 5 Liver weights, liver TG content and FA composition of total liver lipids of dams fed either a control or a CLAsupplemented diet $\left(\mathrm{g} / 100 \mathrm{~g}\right.$ of total FA) ${ }^{\mathrm{a}}$

\begin{tabular}{|c|c|c|c|c|}
\hline & Control & CLA & SEM & $P$ value \\
\hline Liver, g/100 g BW & 5.05 & 5.12 & 0.16 & 0.70 \\
\hline Liver TG, $\mu \mathrm{mol} / \mathrm{g}$ liver & 111 & 84 & 12 & 0.028 \\
\hline C 14:0 & 1.17 & 1.24 & 0.086 & 0.45 \\
\hline C $16: 0$ & 29.7 & 30.1 & 0.84 & 0.69 \\
\hline C 16:1 n9 & 4.80 & 3.85 & 0.40 & 0.026 \\
\hline C 18:0 & 9.25 & 12.7 & 0.77 & $<0.001$ \\
\hline C 18:1 n9 & 31.5 & 28.7 & 1.05 & 0.012 \\
\hline C 18:2 n6 & 15.1 & 12.7 & 0.87 & 0.010 \\
\hline C 18:3 n6 & 1.22 & 0.81 & 0.073 & $<0.001$ \\
\hline C $18: 3$ n3 & 0.32 & 0.29 & 0.027 & 0.33 \\
\hline C18:2 cis-9, trans-11 CLA & $<0.1$ & 0.76 & 0.061 & $<0.001$ \\
\hline C18:2 trans-10, cis-12 CLA & $<0.1$ & 0.33 & 0.033 & $<0.001$ \\
\hline C 20:4 n6 & 5.67 & 7.10 & 0.61 & 0.028 \\
\hline C 22:6 & 1.16 & 1.52 & 0.18 & 0.053 \\
\hline$\Delta-9 \mathrm{D} 16(16: 1 \mathrm{n} 9 / 16: 0)^{\mathrm{b}}$ & 0.16 & 0.13 & 0.011 & 0.0043 \\
\hline$\Delta-9 D 18(18: 1 n 9 / 18: 0)^{b}$ & 3.47 & 2.39 & 0.256 & $<0.001$ \\
\hline$\Delta-6 \mathrm{D}$ n6 $(18: 3 n 6 / 18: 2 n 6)^{b}$ & 0.08 & 0.07 & 0.004 & $<0.001$ \\
\hline
\end{tabular}

${ }^{a}$ Values are means at day 14 of lactation, $n=12-14$. Data were analysed by one-way ANOVA with treatment as fixed effect and animal as random effect ${ }^{b}$ to estimate desaturase activities, desaturase indices were calculated as product-to precursor ratios of individual fatty acids. $\Delta-9 D$ 16, $\Delta-9$ desaturase index for C16:1n9, $\Delta-9 \mathrm{D} 18, \Delta-9$ desaturase index for C18:1n9, $\Delta-6 \mathrm{D}$ n6, $\Delta-6$ desaturase index for the $n 6$ line between groups (Fig. 1a and 1c). Similarly, in the pup's liver, gene expression of TTPA, CYP3A1, LDLR, SCA RB1 and LPL were not influenced by CLA feeding (Fig. 2a). However, in the adipose tissue, gene expression of LDLR and SCARB1 were enhanced in the pups nursed by CLA-fed dams compared to those nursed by control dams (Fig. 2b).

\section{Discussion}

In our study, feed intake and growth of the pregnant and lactating rats was not influenced by dietary supplementation of $0.9 \mathrm{~g}$ of total CLA/100 g of diet. This has been observed by others as well when CLAs were supplemented to rat diets in dosages between 0.25 and $1.35 \mathrm{~g}$ CLA/100 $\mathrm{g}$ of diet $[2,24,25]$. Like in the present study, pup growth has been found unchanged when rat diets were supplemented with 0.25 to $0.5 \mathrm{~g}$ CLA/100 g of diet $[2,24]$. On the other hand, when higher dietary CLA concentrations of 1.35 to $1.47 \mathrm{~g}$ CLA/100 g of the dams' diet have been used, pup growth as well as the dams' milk fat contents was reduced [1, 25]. The observation of our study that the fat contents of the milk curd

Table 6 Apparent tocopherol digestibility and tocopherol concentration in plasma and tissues of dams fed either a control or a CLA-supplemented diet $^{a}$

\begin{tabular}{lllll}
\hline & Control & CLA & SEM & $P$ value \\
\hline Tocopherol digestibility, \% & 77.9 & 68.7 & 2.09 & $<0.001$ \\
Plasma and tissue tocopherol concentrations & & & \\
Plasma, $\mu \mathrm{mol} / \mathrm{l}$ & 22.1 & 24.5 & 1.44 & 0.12 \\
Liver, nmol/g & 491 & 374 & 27.5 & $<0.001$ \\
Adipose tissue, nmol/g & 136 & 199 & 14.2 & $<0.001$ \\
Muscle, nmol/g & 45.0 & 45.3 & 3.29 & 0.91 \\
\hline
\end{tabular}

${ }^{a}$ Values are means at day 14 of lactation, $n=12-14$. Data were analysed by one-way ANOVA with treatment as fixed effect and animal as random effect 
Table 7 Litter development, milk curd fat content and tocopherol concentration in milk curd and tissues of pups nursed by dams fed either a control or a CLA-supplemented diet ${ }^{d}$

\begin{tabular}{|c|c|c|c|c|c|c|c|c|c|c|}
\hline \multirow{2}{*}{$\begin{array}{l}\text { Day after birth } \\
\text { Treatment group }\end{array}$} & \multicolumn{2}{|l|}{1} & \multicolumn{2}{|l|}{7} & \multicolumn{2}{|l|}{14} & \multirow[b]{2}{*}{ SEM } & \multicolumn{3}{|l|}{$P$ value } \\
\hline & Control & CLA & Control & CLA & Control & $\mathrm{CLA}$ & & Treatment & Time & tr.*time \\
\hline \multicolumn{11}{|l|}{ Performance of pups } \\
\hline Litter weight, g & $56.4^{\mathrm{a}}$ & $57.7^{\mathrm{a}}$ & $143^{b}$ & $149^{b}$ & $264^{c}$ & $272^{c}$ & 3.35 & 0.36 & $<0.001$ & 0.48 \\
\hline Pup weight, $g$ & $7.1^{\mathrm{a}}$ & $7.2^{\mathrm{a}}$ & $17.9^{\mathrm{b}}$ & $18.6^{\mathrm{b}}$ & $38.2^{c}$ & $39.2^{c}$ & 0.46 & 0.39 & $<0.001$ & 0.60 \\
\hline \multicolumn{11}{|c|}{ Liver weights and liver triglyceride concentrations } \\
\hline Liver, g/100 g BW & $4.62^{\mathrm{a}}$ & $4.80^{\mathrm{a}}$ & NA & NA & $3.10^{\mathrm{b}}$ & $3.32^{\mathrm{b}}$ & 0.13 & 0.30 & $<0.001$ & 0.92 \\
\hline Liver TG, $\mu \mathrm{mol} / \mathrm{g}$ liver & 32.6 & 48.5 & NA & NA & 40.9 & 36.7 & 3.28 & 0.21 & 0.69 & 0.032 \\
\hline \multicolumn{11}{|l|}{ Fat content } \\
\hline Milk curd, $\mu \mathrm{mol} / \mathrm{g}$ & 299 & 312 & 327 & 292 & 329 & 301 & 6.40 & 0.059 & 0.51 & 0.015 \\
\hline \multicolumn{11}{|l|}{ Tocopherol concentration } \\
\hline Milk curd, $\mathrm{nmol} / \mathrm{g}$ & $500^{a}$ & $429^{a}$ & $57.5^{\mathrm{b}}$ & $55.6^{\mathrm{b}}$ & $65.5^{b}$ & $59.8^{b}$ & 11.4 & 0.084 & $<0.001$ & 0.077 \\
\hline Liver, nmol/g & $381^{\mathrm{a}}$ & $320^{\mathrm{a}}$ & $121^{\mathrm{b}}$ & $102^{b}$ & $102^{\mathrm{b}}$ & $91^{b}$ & 19.2 & 0.21 & $<0.001$ & 0.67 \\
\hline Lung, nmol/g & $35.8^{\mathrm{a}}$ & $39.3^{\mathrm{a}}$ & $72.1^{\mathrm{b}}$ & $67.9^{\mathrm{b}}$ & $65.6^{\mathrm{b}}$ & $71.0^{\mathrm{b}}$ & 2.39 & 0.62 & $<0.001$ & 0.24 \\
\hline Adipose tissue, nmol/g & NA & NA & $52.2^{\mathrm{a}}$ & $50.9^{\mathrm{a}}$ & $49.0^{\mathrm{a}}$ & $71.9^{\mathrm{b}}$ & 2.46 & 0.001 & 0.002 & $<0.001$ \\
\hline
\end{tabular}

${ }^{\mathrm{a}-\mathrm{c}}$ Means with superscripts without a common letter differ at $\mathrm{P}<0.05$. ${ }^{\mathrm{d}}$ Values are means after standardization to 8 pups per litter, $n=12-14$. Means with superscripts without a common letter differ at $P<0.05$. tr., treatment. NA, not analysed. Data were analysed by two-way ANOVA with treatment, time and their interaction as fixed effects and animal as random effect

did not differ between groups fits well to the finding that pup growth was not influenced by CLA feeding of the dams and may be related to the use of lower CLA dosages as compared to the studies of Ringseis et al. [1] and Hayashi et al. [25]. As expected, the CLA concentrations in liver lipids were higher in the CLA group as compared to the control group, which confirms that CLA was incorporated into body lipids. Also, the concentrations of oleic and linoleic acid and of gamma-linoleic acid in liver lipids and the $\Delta-9$ and $\Delta-6$ desaturase indices decreased which can be explained by the t10,c12CLA-induced inhibition of the stearoyl-CoA desaturase
(SCD; $\Delta-9$ desaturase) and the fatty acid desaturase 2 (FADS2; $\Delta-6$ desaturase), respectively [26, 27].

In the dams, our hypothesis that CLA affect body concentrations of tocopherols was confirmed, because the concentrations of tocopherols were decreased in liver and increased in the adipose tissue. This partly confirms findings of Chao et al. [9] and Chen et al. [10] who reported increased concentrations of tocopherols in, amongst others, adipose tissue of growing mice. In general, increased tocopherol concentrations in the adipose tissue could be explained either by an accumulation of tocopherols due to reductions in fat mass or by enhanced deposition of
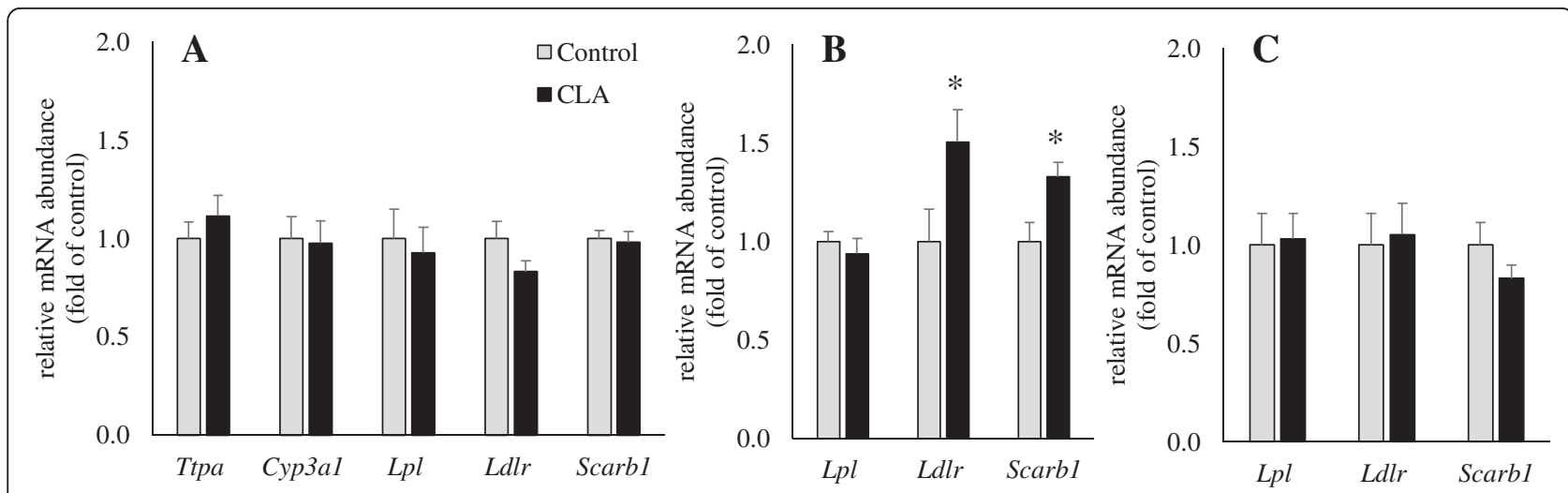

Fig. 1 Relative mRNA abundance of genes involved in lipid and tocopherol metabolism in liver (a), adipose tissue (b) and mammary gland (c) of rats fed either a control or a CLA-supplemented diet. Bars represent mean \pm SEM of 12 to 14 rats per group and are expressed as fold of relative mRNA abundance of the control group. ${ }^{*}$, different from the control group at $P<0.05$. CYP3A1, cytochrome P450, family 3, subfamily A, polypeptide 1; LDLR, low density lipoprotein receptor; $L P L$, lipoprotein lipase; SCARB1, scavenger receptor class B, member 1; TTPA: a-tocopherol transfer protein 

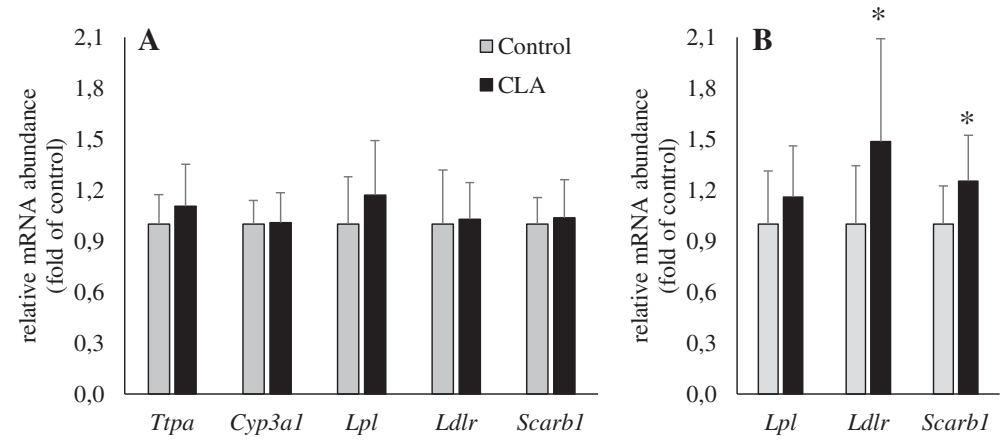

Fig. 2 Relative mRNA abundance of genes involved in lipid and tocopherol metabolism in liver (a) and adipose tissue (b) of pups nursed by dams fed either a control or a CLA-supplemented diet. Bars represent mean \pm SEM of 12 pups per group and are expressed as fold of relative mRNA abundance of the control group. *, different from the control group at $P<0.05$. CYP3A1, cytochrome P450, family 3, subfamily A, polypeptide 1; LDLR, low density lipoprotein receptor; LPL, lipoprotein lipase; SCARB1, scavenger receptor class B, member 1; TTPA: a-tocopherol transfer protein

tocopherols in the adipose tissue or by both processes. We didn't measure adipose tissue mass in the present study and thus cannot exclude a reduction of adipose tissue mass due to CLA feeding as shown by Salgado et al. [28]. However, our data do suggest a reallocation of tocopherols from the liver, where tocopherol concentrations decreased, to the adipose tissue where tocopherol concentrations increased. The finding that liver tocopherol concentrations decreased are in contrast to other studies, which found increased liver tocopherol concentrations after CLA supplementation $[9,10]$. Likewise, our data contrast with that of Chen et al. [10] where tocopherol digestibility was not influenced by CLA-feeding in mice, whereas we observed that tocopherol digestibility in CLA-fed dams was reduced compared to control dams. A reduced tocopherol absorption may help to explain reduced liver tocopherol concentrations due to CLA-feeding in the present study. Also, in contrast to others who have shown that gene expression of the TTPA in the liver of growing mice fed similar dosages of CLA (0.74-0.80 \%) in the diet was enhanced $[9,10]$, the TTPA mRNA concentrations in the liver of the lactating dams in our study were not altered. The TTPA triggers association of $\alpha$-tocopherol with lipoproteins and the secretion from the liver into the bloodstream [7]. It seems also likely that CLA supplementation did not influence tocopherol degradation in the present study, because gene expression of CYP3A1 was similar in both groups and the CYP-dependent $\omega$-hydroxylation of tocopherols is the rate-limiting step in tocopherol degradation [23]. Liver and plasma concentrations of $\alpha$-carboxyethyl hydroxychroman, the degradation product of tocopherol, excreted via urine and bile, have been unchanged by feeding dietary CLA in the study of Chen et al. [10] as well. However, our data indicate that plasma lipoproteins and thus also tocopherols were preferably taken up by the adipose tissue as the gene expression of LDLR and SCARB1, which are involved in uptake of lipids and tocopherols from lipoproteins [7], where enhanced in the adipose tissue, but not increased in liver and mammary gland. In all tissues investigated, gene expression of the LPL, which is involved in TG uptake from VLDL and chylomicrons [29], was not influenced by CLA. This was unexpected because in the mammary gland of both rat $[1]$ and ruminants $[4,5]$, the LPL has been shown to be down-regulated upon CLAfeeding. Interestingly, the uptake of $\alpha$-tocopherol is dependent upon LPL in the mammary gland of lactating rats, but not in adipose tissue [30]. This fits to our observation that tocopherol concentrations were enhanced in the adipose tissue although LPL gene expression was not. The latter is also in line with a study of Andreoli et al. [31], which has shown that the activity of the LPL in white adipose tissue was not influenced when 1.0 or $2.9 \%$ of CLA were included into a rat diet.

The pups' tocopherol intake was probably similar because the tocopherol concentration in the milk curd was similar in both groups. Also, our sampling was done at peak lactation, 14 days after birth, or before which is before onset of solid feed intake by pups occurs ( 18 days after birth) [13], which was also confirmed by visual examination of the pups' stomach contents in our study. Accordingly, the effects of CLA-feeding of the dams on the pups' body tocopherol status was minor and limited to the adipose tissue at the last sampling time point. Only at this time point, at 14 days of age, pups nursing CLA-fed dams had higher adipose tissue tocopherol concentrations than those from the control group, and the increased gene expression of LDLR and SCARB1 indicate that tocopherol uptake into the pup's adipose tissue was increased in pups nursed by CLA-fed dams compared to control dams. Still, we cannot exclude the possibility that the higher tocopherol concentration in the pups' adipose tissue was partly due to a simple concentration effect: the CLA which can be transferred to the pups' body via milk [1] may influence the pups' lipid metabolism as well and reduce adipose tissue mass, which may in turn lead to enhanced tocopherol concentrations in the remaining adipose tissue mass. Together, 
this indicates that dietary CLA supplementation of pregnant and lactating rats in dosages similar to those in the present study do not influence milk tocopherol concentrations and hardly influence tocopherol status in pups.

\section{Conclusions}

In conclusion, we demonstrate that dietary CLA influence tissue tocopherol status in lactating rats. We also present evidence that dietary CLA influence tocopherol metabolism on gene expression level. Based on our data, we conclude that CLA increases liver export of $\alpha$ tocopherol and uptake of tocopherols from lipoproteins into the adipose tissue but not into mammary gland. We also show that CLA has only minimal effects on tissue tocopherol status of pups nursed by CLA-fed dams although it seems that the CLA transferred to pups via milk affect the pup's tocopherol metabolism similar than it does in dams. These data indicate that supplementation of CLA in pregnant and lactating animals is uncritical in terms of tocopherol status of new-borns.

\section{Abbreviations}

ACTB, actin, beta; ANOVA, analysis of variance; ATP5B, ATP synthase, H+ transporting, mitochondrial F1 complex, beta polypeptide; CANX, calnexin; CLA, conjugated linoleic acid; CYP3A1, cytochrome P450, family 3, subfamily A, polypeptide 1; FA, fatty acid; HiP, hexane: isopropanol; HPLC, high-performance liquid chromatography; LDLR, low density lipoprotein receptor; $L P L$, lipoprotein lipase; MDH1, malate dehydrogenase 1, NAD (soluble); RPL13, ribosomal protein L13; SCARB1, scavenger receptor class B, member 1; SCD, stearoyl-CoA desaturase; SD, standard deviation; TG, triglyceride; TOP1, topoisomerase (DNA) I; TTPA, a-tocopherol transfer protein; VLDL, very low density lipoprotein; YWHAZ, tyrosine 3-monooxygenase/tryptophan 5-monooxygenase activation protein, zeta.

\section{Acknowledgements}

The authors thank $D$. Zahner for the possibility to perform the experiment at the central animal facility (ZTL), Giessen, and for organisational help. They also thank C. Spangenberg for preparing the diets, C. Stellwagen for care of the animals, and M. Jäger and N. Krämer for tocopherol, TG and FA analyses.

\section{Authors' contributions}

JZ and KE designed the research. JZ conducted the research, analysed the data and wrote the manuscript. EM was responsible for tocopherol and FA analyses and analysed the data. All authors read and approved the final manuscript.

\section{Competing interests}

The authors declare that they have no competing interests.

Received: 4 September 2015 Accepted: 24 May 2016

Published online: 31 May 2016

\section{References}

1. Ringseis R, Saal D, Muller A, Steinhart H, Eder K. Dietary conjugated linoleic acids lower the triacylglycerol concentration in the milk of lactating rats and impair the growth and increase the mortality of their suckling pups. J Nutr. 2004;134:3327-34.

2. Poulos SP, Sisk M, Hausman DB, Azain MJ, Hausman GJ. Pre- and postnatal dietary conjugated linoleic acid alters adipose development, body weight gain and body composition in Sprague-Dawley rats. J Nutr. 2001;131:2722-31.

3. Tous N, Theil PK, Lauridsen C, Lizardo R, Vila B, Esteve-Garcia E. Dietary conjugated linoleic acid modify gene expression in liver, muscles, and fat tissues of finishing pigs. J Anim Sci. 2012;90 Suppl 4:340-2.

4. Gervais R, McFadden JW, Lengi AJ, Corl BA, Chouinard PY. Effects of intravenous infusion of trans-10, cis-12 18: 2 on mammary lipid metabolism in lactating dairy cows. J Dairy Sci. 2009;92:5167-77.
5. Schlegel G, Ringseis R, Shibani M, Most E, Schuster M, Schwarz FJ, et al. Influence of a rumen-protected conjugated linoleic acid mixture on carcass traits and meat quality in young simmental heifers. J Anim Sci. 2012;90:1532-40.

6. Gutgesell A, Ringseis R, Eder K. Short communication: Dietary conjugated linoleic acid down-regulates fatty acid transporters in the mammary glands of lactating rats. J Dairy Sci. 2009;92:1169-73.

7. Lemaire-Ewing S, Desrumaux C, Neel D, Lagrost L. Vitamin E transport, membrane incorporation and cell metabolism: Is alpha-tocopherol in lipid rafts an oar in the lifeboat? Mol Nutr Food Res. 2010;54:631-40.

8. Kersten S. Physiological regulation of lipoprotein lipase. Biochim Biophys Acta. 1841;2014:919-33.

9. Chao P, Chen W, Liao C, Shaw H. Conjugated linoleic acid causes a marked increase in liver alpha-tocopherol and liver alpha-tocopherol transfer protein in C57BL/6 J mice. Int J Vitam Nutr Res. 2010;80:65-73.

10. Chen W, Li Y, Wang M, Kang Z, Huang H, Shaw H. Elevation of tissue alphatocopherol levels by conjugated linoleic acid in C57BL/6 J mice is not associated with changes in vitamin E absorption or alpha-carboxyethyl hydroxychroman production. Nutr. 2012;28:59-66.

11. Reeves PG, Nielsen FH, Fahey GC. AIN-93 AIN-93 purified diets for laboratory rodents: final report of the American Institute of Nutrition ad hoc writing committee on the reformulation of the AIN-76A rodent diet. J Nutr. 1993; 123:1939-51.

12. Cramer CP, Thiels E, Alberts JR. Weaning in rats: I. Maternal behavior. Dev Psychobiol. 1990;23:479-93.

13. Thiels E, Alberts JR, Cramer CP. Weaning in rats: II. Pup behavior patterns. Dev Psychobiol. 1990;23:495-510.

14. Hara A, Radin NS. Lipid extraction of tissues with a low-toxicity solvent. Anal Biochem. 1978:90:420-6.

15. Butte W. Rapid method for the determination of fatty acid profiles from fats and oils using trimethylsulphonium hydroxide for transesterification. J Chromatogr. 1983;261:142-5.

16. Masek T, Filipovic N, Hamzic LF, Puljak L, Starcevic K. Long-term streptozotocin diabetes impairs arachidonic and docosahexaenoic acid metabolism and $\Delta 5$ desaturation indices in aged rats. Exp Gerontol. 2014;60:140-6.

17. Biesalski HK, Köhrle J, Schümann K. Vitamine, Spurenelemente und Mineralstoffe. Prävention und Therapie mit Mikronährstoffen. Georg Thieme Verlag: Stuttgart, New York; 2002

18. Brandt $\mathrm{M}$, Allam SM. Analytik von $\mathrm{TiO}_{2}$ in Darminhalt und Kot nach Kjeldahlaufschluss. Arch Anim Nutr. 1987;37:453-4.

19. Couturier A, Ringseis R, Mooren F, Krüger K, Most E, Eder K. Carnitine supplementation to obese Zucker rats prevents obesity-induced type II to type I muscle fiber transition and favors an oxidative phenotype of skeletal muscle. Nutr Metab (Lond). 2013;10:48.

20. Livak K, Schmittgen TD. Analysis of relative gene expression data using real-time quantitative PCR and the 2(-Delta Delta C(T)) Method. Methods. 2001;25:402-8.

21. Vandesompele J, Preter K de, Pattyn F, Poppe B, van Roy N, Paepe A de, et al. Accurate normalization of real-time quantitative RT-PCR data by geometric averaging of multiple internal control genes. Genome Biol. 2002; 3:RESEARCH0034.

22. Martignoni M, Groothuis GMM, de Kanter R. Species differences between mouse, rat, dog, monkey and human CYP-mediated drug metabolism, inhibition and induction. Expert Opin Drug Metab Toxicol. 2006;2:875-94.

23. Abe C, Uchida T, Ohta M, Ichikawa T, Yamashita K, Ikeda S. Cytochrome P450-dependent metabolism of vitamin $\mathrm{E}$ isoforms is a critical determinant of their tissue concentrations in rats. Lipids. 2007;42:637-45.

24. Chin SF, Storkson JM, Albright K, Cook ME, Pariza MW. Conjugated linoleic acid is a growth factor for rats as shown by enhanced weight gain and improved feed efficiency. J Nutr. 1994;124:2344-9.

25. Hayashi AA, de Medeiros SR, Carvalho MH, Lanna DPD. Conjugated linoleic acid (CLA) effects on pups growth, milk composition and lipogenic enzymes in lactating rats. J Dairy Res. 2007;74:160-6.

26. Bretillon L, Chardigny JM, Grégoire S, Berdeaux O, Sébédio JL. Effects of conjugated linoleic acid isomers on the hepatic microsomal desaturation activities in vitro. Lipids. 1999;34:965-9.

27. Eder K, Slomma S, Becker K. Trans-10, cis-12 conjugated linoleic acid suppresses the desaturation of linoleic and a-linolenic acids in HepG2 cells. J Nutr. 2002;132:1115-21.

28. Salgado JM, Ferreira TRB, Donado-Pestana CM, de Almeida OC, das Neves AMR, Mansi DN, et al. Conjugated linoleic acid combined with physical 
activity reduces body fat accumulation but does not modify lean body mass in male and female Wistar rats. J Med Food. 2012;15:406-12

29. Goldberg IJ, Eckel RH, Abumrad NA. Regulation of fatty acid uptake into tissues: lipoprotein lipase- and CD36-mediated pathways. J Lipid Res. 2009; 50(Suppl):S86-90.

30. Martinez S, Barbas C, Herrera E. Uptake of alpha-tocopherol by the mammary gland but not by white adipose tissue is dependent on lipoprotein lipase activity around parturition and during lactation in the rat. Metab Clin Exp. 2002:51:1444-51.

31. Andreoli MF, Illesca PG, González MA, Bernal CA. Conjugated linoleic acid reduces hepatic steatosis and restores liver triacylglycerol secretion and the fatty acid profile during protein repletion in rats. Lipids. 2010;45:1035-45.

32. Souci SW, Fachmann W, Kraut H. Die Zusammensetzung der Lebensmittel. Nährwert-tabellen. 7th ed. Stuttgart: MedPharm Scientific Publishers; 2008.

\section{Submit your next manuscript to BioMed Central} and we will help you at every step:

- We accept pre-submission inquiries

- Our selector tool helps you to find the most relevant journal

- We provide round the clock customer support

- Convenient online submission

- Thorough peer review

- Inclusion in PubMed and all major indexing services

- Maximum visibility for your research

Submit your manuscript at www.biomedcentral.com/submit 